\title{
Statistical optimization of process parameters for the production of tannase by Aspergillus flavus under submerged fermentation
}

\author{
S. K. Mohan · T. Viruthagiri $\cdot$ C. Arunkumar
}

Received: 12 March 2013/ Accepted: 7 May 2013/Published online: 25 May 2013

(C) The Author(s) 2013. This article is published with open access at Springerlink.com

\begin{abstract}
Production of tannase by Aspergillus flavus (MTCC 3783) using tamarind seed powder as substrate was studied in submerged fermentation. Plackett-Burman design was applied for the screening of 12 medium nutrients. From the results, the significant nutrients were identified as tannic acid, magnesium sulfate, ferrous sulfate and ammonium sulfate. Further the optimization of process parameters was carried out using response surface methodology (RSM). RSM has been applied for designing of experiments to evaluate the interactive effects through a full 31 factorial design. The optimum conditions were tannic acid concentration, $3.22 \%$; fermentation period, $96 \mathrm{~h}$; temperature, $35.1{ }^{\circ} \mathrm{C}$; and $\mathrm{pH}$ 5.4. Higher value of the regression coefficient $\left(R^{2}=0.9638\right)$ indicates excellent evaluation of experimental data by second-order polynomial regression model. The RSM revealed that a maximum tannase production of $139.3 \mathrm{U} / \mathrm{ml}$ was obtained at the optimum conditions.
\end{abstract}

Keywords Tannase - Response surface methodology · Plackett-Burman design · Submerged fermentation

\section{Introduction}

Tannin acyl hydrolase (EC 3.1.1.20), commonly known as tannase, catalyses the hydrolysis of ester and depside bonds in hydrolysable tannins such as tannic acid, resulting glucose and gallic acid (Lekha and Lonsane 1997). Tannase is extensively used in the preparation of instant tea, beer,

S. K. Mohan $(\bowtie) \cdot T$. Viruthagiri · C. Arunkumar

Department of Chemical Engineering, Annamalai University, Annamalainagar 608002, Tamilnadu, India

e-mail:skmohan75@gmail.com wine, coffee flavored soft drinks, etc. Tannase is also used in the production of gallic acid, a substrate for chemical synthesis of propyl gallate and trimethoprim which have application in food and pharmaceutical industries (Das Mohapatra et al. 2006; Lekha and Lonsane 1994). Many fungi, such as Aspergillii, Penicillii, Fusaria, and Trichoderma (Mohan et al. 2012; Batra and Saxena 2005; Murugan et al. 2007; Paranthaman et al. 2009), yeast like Candida sp., and Saccharomyces cerevisiae (Mondal et al. 2001a) have been reported as tannase producers. Few bacteria like Bacilli, Corynebacterium sp., Lactobacillus sp., and Serratia sp. are known to produce tannase (Rodríguez et al. 2008; Milva et al. 2010).

In industrial level tannase is mainly produced by Aspergillus species under submerged fermentation $(\mathrm{SmF})$. The SmF is widely used for enzyme production because it offers many advantages like uniform process conditions, viz. concentration, temperature, $\mathrm{pH}$, aeration and agitation in the bioreactors (Lekha and Lonsane 1997). In addition, the utilization of agro-industrial wastes, on one hand, provides alternative substrates and, on the other hand, helps to solve pollution problems by eliminating the need for disposal of the wastes. The nature of the substrate employed is the most important factor affecting fermentation processes, and its selection depends upon several factors mainly related to cost and availability and, thus, may necessitate the screening of several agro-industrial residues (Couto and Sanroman 2006).

The use of a sequential experimental design strategy is a useful tool for process optimization. Response surface methodology (RSM) provides important information regarding the optimum level of each variable along with its interactions with other variables and their effects on product yield. It reduces the number of experiments without neglecting the interactions among the parameters. 
This multivariate approach also improves statistical interpretation possibilities and evaluates the relative significance of several contributing factors even in the presence of complex interactions (Dilipkumar et al. 2011). RSM is widely used for multivariable optimization studies in several biotechnological processes such as the optimization of media, process conditions, hydrogen production, fermentation, sorption of dyes, etc. (Mannan et al. 2007; Pan et al. 2008). In the present work, optimization of tannase production by Aspergillus flavus sp. using tamarind seed powder as substrate was carried out using a sequential strategy of the experimental design. So far no work is available on the production of tannase using tamarind seed as substrate. Tamarind seed powder is a cheap substrate which is abundantly available in southern part of India. Hence, it was selected as substrate for the production of tannase.

\section{Materials and methods}

Microorganism and culture conditions

The tannase producing fungal culture, A. flavus (MTCC 3783) was obtained from IMTECH, Chandigarh and used for tannase production. The fungal culture was maintained on Czapek Dox minimal media agar slants supplemented with $1 \%$ tannic acid as the sole carbon source. The fungal strain was sub-cultured periodically, grown at $30^{\circ} \mathrm{C}$ for 7 days. The well grown culture was stored at $4{ }^{\circ} \mathrm{C}$ in a refrigerator and used for further sub-culturing.

The composition of the Czapek Dox minimal medium used for tannase enzyme production was: tannic acid, $10 \mathrm{~g} /$ 1; sodium nitrate, $6 \mathrm{~g} / \mathrm{l}$; potassium dihydrogen orthophosphate, $1.52 \mathrm{~g} / \mathrm{l}$; magnesium sulfate, $0.52 \mathrm{~g} / \mathrm{l}$; potassium chloride, $0.52 \mathrm{~g} / \mathrm{l}$; ferrous sulfate, $0.01 \mathrm{~g} / 1$ and zinc sulfate, $0.01 \mathrm{~g} / \mathrm{l}$. Cells were harvested from slants and used to inoculate liquid medium.

Production of tannase in submerged fermentation (SmF)

The spore suspension was inoculated in $250 \mathrm{ml}$ Erlenmeyer flask containing $100 \mathrm{ml}$ of Czapek Dox minimal medium. $3 \mathrm{gm}$ of substrate (tamarind seed) was added separately to the above mentioned medium for studying their effect on the enzyme production. The cultures were grown at $30{ }^{\circ} \mathrm{C}$, $140 \mathrm{rpm}$ for 6 days in an incubator shaker. The samples were withdrawn at regular intervals of $24 \mathrm{~h}$. The biomass was separated by filtering through Whatman No.1 filter paper. The cell free culture broth was assayed for the tannase activity.
Assay of tannase

$0.1 \mathrm{ml}$ of enzyme solution was incubated with $0.3 \mathrm{ml}$ of $1.0 \%(\mathrm{w} / \mathrm{v})$ tannic acid and $0.2 \mathrm{M}$ acetate buffer $(\mathrm{pH} 5.0)$ at $40{ }^{\circ} \mathrm{C}$ for $10 \mathrm{~min}$ and then the enzyme production was stopped by cooling to $0{ }^{\circ} \mathrm{C}$ by the addition of $2 \mathrm{ml}$ bovine serum albumin (BSA) $(1 \mathrm{mg} / \mathrm{ml})$, which precipitates the remaining tannic acid. Simultaneously, a control without the enzyme was incubated and the samples were analyzed. The tubes were then centrifuged $(5,000 \times g, 10 \mathrm{~min})$ and the precipitate was dissolved in $2 \mathrm{ml}$ of sodium dodecyl sulfate (SDS) - triethanolamine (1\% w/v SDS in $5 \% \mathrm{v} / \mathrm{v}$ triethanolamine) solution and the absorbency was measured at $550 \mathrm{~nm}$ after addition of $1 \mathrm{ml}$ of $\mathrm{FeCl}_{3}\left(0.01 \mathrm{M} \mathrm{FeCl}_{3}\right.$ in $0.01 \mathrm{~N} \mathrm{HCl}$ ) (Mondal et al. 2001b). One unit of tannase enzyme was defined as the amount of enzyme required to hydrolyze one micro mole of ester linkage of tannic acid in $1 \mathrm{~min}$ at specific condition.

\section{Plackett-Burman design}

Plackett-Burman design, an efficient technique for medium component selection (Plackett-Burman 1946) was used to determine the factors that significantly influence the tannase production. Twelve variables (Table 1 ) were screened in 20 experimental runs (Table 2) and the insignificant variables were eliminated to obtain a smaller, more manageable set of factors. The low level $(-1)$ and high level $(+1)$ of each factor are listed in Table 1. The statistical software package 'Design Expert 7.1.5' was used for analyzing the experimental data.

Table 1 Nutrient screening using a Plackett-Burman design

\begin{tabular}{llll}
\hline Levels $(\mathrm{g} / \mathrm{ml})$ & & \\
\hline $\begin{array}{l}\text { Nutrient } \\
\text { code }\end{array}$ & Nutrient & $\begin{array}{l}\text { Low } \\
(-1)\end{array}$ & $\begin{array}{l}\text { High } \\
(+1)\end{array}$ \\
\hline $\mathrm{A}$ & Tannic acid & 1 & 5 \\
$\mathrm{~B}$ & Yeast extract & 0.1 & 1 \\
$\mathrm{C}$ & Magnesium sulfate & 0.1 & 1 \\
$\mathrm{D}$ & Ferrous sulfate & 0.1 & 1 \\
$\mathrm{E}$ & Ammonium nitrate & 0.1 & 1 \\
$\mathrm{~F}$ & Ammonium chloride & 0.1 & 1 \\
$\mathrm{G}$ & Urea & 0.1 & 1 \\
$\mathrm{H}$ & Potassium chloride & 0.1 & 1 \\
$\mathrm{I}$ & Sodium nitrate & 0.1 & 1 \\
$\mathrm{~J}$ & Potassium dihydrogen phosphate & 0.1 & 1 \\
$\mathrm{~K}$ & Ammonium sulfate & 0.1 & 1 \\
L & Peptone & 0.1 & 1 \\
\hline
\end{tabular}




\section{Box-Behnken design}

The process variables with significant effects on enzyme production were optimized using Box-Behnken design. To determine the response pattern and synergy of variables the full $2^{k}$ composite design was performed giving $2^{k}+2 k+n_{0}$ combinations where $k$ is the number of independent variables and $n_{0}$ is the number of replications of the experiments at center point. This provided 31 experimental runs performed with four factors at five coded levels $(-2,-1,0,+1$ and +2$)$ in duplicate, with central points in triplicate to determine the experimental error (Box and Draper 1987). The coded and actual values of the variables are presented in Table 3 . The responses of the input variables were evaluated as a function of tannase activity, measured as the amount of tannase liberated and coded by $\mathrm{Y}(\mathrm{U} / \mathrm{ml})$ (Table 4$)$. A multiple regression analysis of the data was carried out to obtain an empirical model that relates the measured response to the independent variables. A second-order polynomial equation was obtained.

$Y=\beta_{0}+\sum \beta_{i} X_{i}+\sum \beta_{i i} X_{i}^{2}+\sum \sum \beta_{i j} X_{i} X_{j}$

where $Y$ is the predicted response, $\beta_{0}$ is the intercept, $\beta_{i}$ is the linear coefficient, $\beta_{i i}$ is the quadratic coefficient and $\beta_{i j}$ is the interaction coefficient. The relation between the coded forms of the input variable and the actual values of chosen variables is described as follows:

$x_{i}=\left(X_{i}-X_{0}\right) / \Delta X_{i} \quad i=1,2,3, \ldots, K$

where $x_{i}$ is the coded value, $X_{i}$ is the actual value of an independent variable, $X_{0}$ is the value of $X_{i}$ at center point and $\Delta X_{i}$ is the step change of the variable and $i=1-4$. The analysis of results was performed with statistical and graphical analysis software (Design expert 7.1.5). The software was used for regression analysis of data obtained and to estimate the coefficient of regression equation. ANOVA (analysis of variance) for the final predictive equation and optimization values were also obtained using the same software package which indicates whether the variable was more significant or less significant.

\section{Results and discussion}

\section{Screening of nutrients by PBD}

Experiments were carried out based on Plackett-Burman design and the results obtained were given in Table 2. From the table, it was observed that the variation in tannase activity was 30-90 U/ml. From the Pareto chart (Fig. 1), the nutrients, tannic acid, magnesium sulfate, ferrous

Table 2 Plackett-Burman experimental design matrix for screening of important variables for tannase production using Aspergillus flavus

\begin{tabular}{|c|c|c|c|c|c|c|c|c|c|c|c|c|c|}
\hline Run no. & $A$ & $B$ & $C$ & $D$ & $E$ & $F$ & $G$ & $H$ & $I$ & $J$ & $K$ & $L$ & Tannase $(\mathrm{U} / \mathrm{ml})$ \\
\hline 1 & 1 & 1 & 1 & 1 & -1 & -1 & 1 & 1 & -1 & 1 & 1 & -1 & 38.20 \\
\hline 2 & -1 & 1 & -1 & 1 & -1 & 1 & 1 & 1 & 1 & -1 & -1 & 1 & 65.40 \\
\hline 3 & -1 & -1 & -1 & -1 & 1 & -1 & 1 & 1 & 1 & 1 & -1 & -1 & 95.52 \\
\hline 4 & -1 & 1 & 1 & -1 & -1 & -1 & -1 & 1 & -1 & 1 & -1 & 1 & 80.82 \\
\hline 5 & 1 & -1 & 1 & -1 & 1 & 1 & 1 & 1 & -1 & -1 & 1 & 1 & 39.67 \\
\hline 6 & 1 & -1 & -1 & -1 & -1 & 1 & -1 & 1 & -1 & 1 & 1 & 1 & 58.80 \\
\hline 7 & -1 & -1 & -1 & 1 & -1 & 1 & -1 & 1 & 1 & 1 & 1 & -1 & 42.80 \\
\hline 8 & 1 & -1 & 1 & 1 & -1 & -1 & -1 & -1 & 1 & -1 & 1 & -1 & 30.87 \\
\hline 9 & -1 & 1 & -1 & -1 & 1 & -1 & -1 & -1 & -1 & -1 & 1 & -1 & 50.89 \\
\hline 10 & -1 & 1 & -1 & -1 & 1 & 1 & -1 & 1 & 1 & -1 & -1 & -1 & 88.76 \\
\hline 11 & -1 & -1 & -1 & -1 & -1 & -1 & -1 & -1 & -1 & -1 & -1 & -1 & 90.76 \\
\hline 12 & -1 & 1 & 1 & 1 & 1 & -1 & -1 & 1 & 1 & -1 & 1 & 1 & 43.90 \\
\hline 13 & -1 & -1 & 1 & 1 & -1 & 1 & 1 & -1 & -1 & -1 & -1 & 1 & 57.90 \\
\hline 14 & -1 & -1 & -1 & -1 & 1 & -1 & 1 & -1 & 1 & 1 & 1 & 1 & 86.54 \\
\hline 15 & 1 & -1 & 1 & 1 & 1 & 1 & -1 & -1 & 1 & 1 & -1 & 1 & 38.00 \\
\hline 16 & -1 & 1 & -1 & 1 & 1 & 1 & 1 & -1 & -1 & 1 & 1 & -1 & 54.89 \\
\hline 17 & 1 & 1 & 1 & -1 & -1 & 1 & 1 & -1 & 1 & 1 & -1 & -1 & 47.02 \\
\hline 18 & 1 & 1 & -1 & -1 & -1 & -1 & 1 & -1 & 1 & -1 & 1 & 1 & 60.76 \\
\hline 19 & 1 & -1 & -1 & 1 & 1 & -1 & 1 & 1 & -1 & -1 & -1 & -1 & 56.76 \\
\hline 20 & 1 & 1 & -1 & 1 & 1 & -1 & -1 & -1 & -1 & 1 & -1 & 1 & 69.00 \\
\hline
\end{tabular}


Table 3 Ranges of the independent variables used in RSM

\begin{tabular}{llrrrrr}
\hline Variables & \multicolumn{2}{l}{ Levels $(\mathrm{U} / \mathrm{ml})$} & & \\
\cline { 2 - 6 } & Code & -2 & -1 & 0 & +1 & +2 \\
\hline Tannic acid conc. $(\%)$ & $X_{1}$ & 1 & 2 & 3 & 4 & 5 \\
Fermentation period $(\mathrm{h})$ & $X_{2}$ & 48 & 72 & 96 & 120 & 144 \\
Temperature $\left({ }^{\circ} \mathrm{C}\right)$ & $X_{3}$ & 25 & 30 & 35 & 40 & 45 \\
$\mathrm{pH}$ & $X_{4}$ & 4.5 & 5 & 5.5 & 6 & 6.5 \\
\hline
\end{tabular}

Table 4 Central composite design (CCD) of factors in coded levels with enzyme activity as response

\begin{tabular}{|c|c|c|c|c|c|c|}
\hline \multirow[t]{2}{*}{ Run no. } & \multirow[t]{2}{*}{$X_{1}$} & \multirow[t]{2}{*}{$X_{2}$} & \multirow[t]{2}{*}{$X_{3}$} & \multirow[t]{2}{*}{$X_{4}$} & \multicolumn{2}{|c|}{ Tannase activity $(\mathrm{U} / \mathrm{ml})$} \\
\hline & & & & & Experimental & Predicted \\
\hline 1 & 0 & 0 & 2 & 0 & 100.45 & 95.98 \\
\hline 2 & 0 & 0 & -2 & 0 & 94.6 & 90.37 \\
\hline 3 & 0 & 0 & 0 & 0 & 137.54 & 134.71 \\
\hline 4 & 0 & -2 & 0 & 0 & 98.5 & 94.96 \\
\hline 5 & -1 & 1 & -1 & 1 & 78.5 & 81.94 \\
\hline 6 & -1 & -1 & -1 & 1 & 85.5 & 84.56 \\
\hline 7 & 1 & 1 & -1 & 1 & 90.67 & 94.55 \\
\hline 8 & 1 & 1 & 1 & -1 & 95.67 & 98.75 \\
\hline 9 & 0 & 0 & 0 & 2 & 90.54 & 85.72 \\
\hline 10 & -1 & 1 & -1 & -1 & 99.54 & 99.19 \\
\hline 11 & 0 & 0 & 0 & 0 & 134.32 & 134.71 \\
\hline 12 & -1 & -1 & 1 & -1 & 100.43 & 98.91 \\
\hline 13 & 1 & -1 & 1 & -1 & 95.7 & 98.61 \\
\hline 14 & 0 & 0 & 0 & 0 & 134.23 & 134.71 \\
\hline 15 & 0 & 0 & 0 & 0 & 134.13 & 134.71 \\
\hline 16 & 1 & -1 & -1 & 1 & 95.34 & 97.73 \\
\hline 17 & 0 & 0 & 0 & 0 & 134.22 & 92.49 \\
\hline 18 & 0 & 0 & 0 & 0 & 134.31 & 134.71 \\
\hline 19 & 1 & 1 & 1 & 1 & 97.43 & 97.73 \\
\hline 20 & 0 & 2 & 0 & 0 & 97.65 & 92.49 \\
\hline 21 & 1 & 1 & -1 & -1 & 103.21 & 105.65 \\
\hline 22 & 0 & 0 & 0 & 0 & 134.23 & 134.71 \\
\hline 23 & -1 & 1 & 1 & 1 & 90.36 & 92.72 \\
\hline 24 & -1 & -1 & 1 & 1 & 93.15 & 97.06 \\
\hline 25 & -1 & 1 & 1 & -1 & 96.22 & 99.90 \\
\hline 26 & -1 & -1 & -1 & -1 & 90.43 & 96.48 \\
\hline 27 & -2 & 0 & 0 & 0 & 106.4 & 102.44 \\
\hline 28 & 1 & -1 & 1 & 1 & 100.2 & 102.913 \\
\hline 29 & 0 & 0 & 0 & -2 & 102.56 & 98.67 \\
\hline 30 & 2 & 0 & 0 & 0 & 119.5 & 114.75 \\
\hline 31 & 1 & 1 & 1 & -1 & 98.4 & 98.76 \\
\hline
\end{tabular}

sulfate and potassium dihydrogen phosphate were found to be significant for the production of tannase by A. flavus sp. using tamarind seed powder as substrate.

The equation obtained was

$$
\begin{aligned}
Y= & -14.35 \mathrm{~A}-2.268 \mathrm{~B}-14.49 \mathrm{C}-14.81 \mathrm{D} \\
& -0.310 \mathrm{E}-10.348 \mathrm{~F}+3.276 \mathrm{G}+2.0 \mathrm{H}-0.212 \mathrm{I} \\
& -5.062 \mathrm{~J}-17.86 \mathrm{~K}+5.80 \mathrm{~L}
\end{aligned}
$$


where A, tannic acid; B, yeast extract; $\mathrm{C}$, magnesium sulfate; D, ferrous sulfate; E, ammonium nitrate; $F$, ammonium chloride; $\mathrm{G}$, urea; $\mathrm{H}$, potassium chloride; $\mathrm{I}$, sodium nitrate; J, potassium dihydrogen phosphate; K, ammonium sulfate; $\mathrm{L}$, peptone.

From the above equation, the negative coefficient for $\mathrm{K}$, $\mathrm{D}, \mathrm{A}$ and $\mathrm{C}$ indicates that increase in the nutrient concentration decreases the tannase activity. Hence their levels were maintained at their low $(-1)$ levels in the optimization of process variables.

\section{Optimization of process parameters by RSM}

The levels of the factors (tannic acid concentration, fermentation period, temperature and $\mathrm{pH}$ ) and the effect of their interactions on tannase production were determined by central composite design of RSM. Thirty-one experiments were performed with different combinations of the factors shown in Table 4. The predicted and observed responses along with the design matrix were presented in Table 5. The results were analyzed by ANOVA. The second-order regression equation provided levels of tannase activity as a function of tannic acid concentration, fermentation period, temperature and $\mathrm{pH}$ which can be presented in terms of coded factors as in the following equation:

$$
\begin{aligned}
Y= & 134.711+3.07708 X_{1}-0.6183 X_{2}+1.4033 X_{3} \\
& -3.2354 X_{4}-6.5288 X_{1}^{2}-10.2475 X_{2}^{2}-10.3850 X_{3}^{2} \\
& -10.6288 X_{4}^{2}-0.21 X_{1} X_{2}-1.90 X_{1} X_{3}+1.5381 X_{1} X_{4} \\
& -0.4306 X_{2} X_{3}-1.3325 X_{2} X_{4}+2.5175 X_{3} X_{4}
\end{aligned}
$$

where $Y$ is the tannase activity $(\mathrm{U} / \mathrm{ml})$ produced as a function of the coded levels of tannic acid concentration $\left(X_{1}\right)$, fermentation period $\left(X_{2}\right)$, temperature $\left(X_{3}\right)$ and $\mathrm{pH}$ $\left(X_{4}\right)$.

The ANOVA for tannase production was given in Table 5. A Model $\mathrm{F}$ value of 28.49 implies the model was

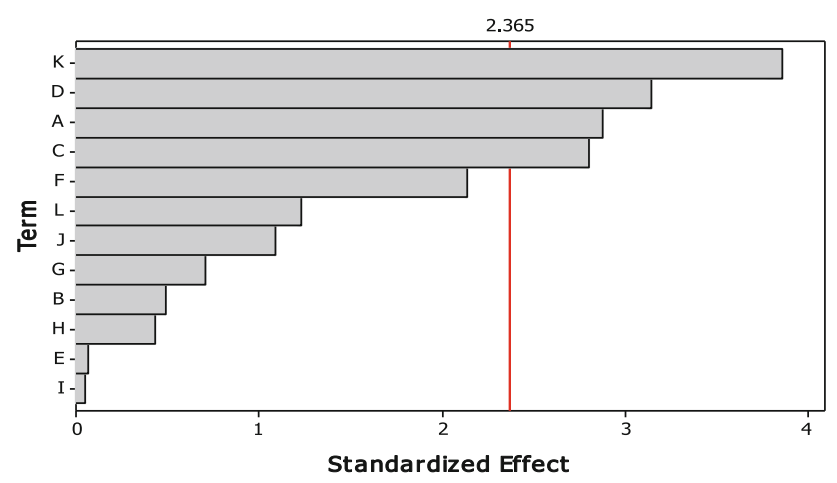

Fig. 1 Pareto chart showing the effect of media components on tannase activity using Aspergillus flavus significant. Values of "Prob $>F$ " $<0.05$ indicate the model terms were significant. Values $>0.1$ indicate the model terms were not significant. In the present work, the linear effect of tannic acid concentration and $\mathrm{pH}$, square effects of $X_{1}, X_{2}, X_{3}$ and $X_{4}$ and interactive effects of $X_{3}$ and $X_{4}$ were significant for tannase production. The coefficient of determination $\left(R^{2}\right)$ for the tannase activity was calculated as 0.9638 , which is close to 1 and can account for up to $96.38 \%$ of the variability of the response. The predicted $R^{2}$ value of 0.7785 is in reasonable agreement with the adjusted $R^{2}$ value of 0.9299 . An adequate precision value $>4$ is desirable. The adequate precision value of 16.64 indicates an adequate signal and suggests that the model can be used to navigate the design space. The coefficient of variation $(\mathrm{CV})$ indicates the degree of precision with which the experiments are compared. Generally, the higher the value of the $\mathrm{CV}$ is the lower the reliability of the experiment. Here a lower value of CV (4.30) indicates greater reliability of the experiments performed. The above model can be used to predict the tannase production within the limits of the experimental factors.

\section{Response surface plots}

The interactive effects of variables on tannase production were studied by plotting 3D surface curves against two independent variables, while keeping the other variable at its central (0) level. The 3D curves of the calculated tannase production and contour plots from the interactions between the variables were shown in Figs. 2, 3, 4 and 5. Figure 2 shows the dependency of tannase on tannic acid concentration and fermentation period. The tannase activity increased with an increase in tannic acid concentration to about $3.22 \%$. Tannic acid is an inducer for the production of tannase and hence tannic acid activity increases. But at higher concentration (above $3.22 \%$ ) tannase activity decreases. This may be due to inducer solubility, toxicity level and saturation which determine the optimum concentration (Pinto 2003).

From Fig. 2, it was also inferred that an increase in fermentation period resulted in an increase in tannase activity up to $96 \mathrm{~h}$ after that the tannase activity decreases. A decline in enzyme activity after $96 \mathrm{~h}$ of fermentation may be due to decrease in nutrient availability in the medium. These are in agreements with the results obtained by Beniwal and Chhokar (2010). Figures 4 and 5 show the dependency of tannase activity on temperature. Generally, temperature influences the metabolic activity of cells. At lower and higher temperatures, the tannase activity was found to be low. The maximum tannase activity was observed at a temperature of $35.1{ }^{\circ} \mathrm{C}$. These results are well supported by Beniwal and Chhokar (2010). Similarly for $\mathrm{pH}$, at low and higher levels the activity was low 
Table 5 Analysis of variance (ANOVA) for response surface quadratic model for the production of tannase

Std. Dev. 4.49; $R^{2}$ 0.9638; Mean 104.33; Adj $R^{2}$ 0.9299; CV \% 4.30; Pred $R^{2} 0.7785$; Adeq Precision 16.644

Fig. 2 3D plot showing the effect of tannic acid concentration and fermentation period on tannase activity

\begin{tabular}{lccrrr}
\hline Source & Coefficient factor & Sum of squares & $D F$ & $F$ & $P>F$ \\
\hline Model & 134.79 & $8,045.48$ & 14 & 28.49 & $<0.0001$ \\
$X_{1}$ & 3.08 & 209.76 & 1 & 10.40 & 0.0057 \\
$X_{2}$ & -0.62 & 8.64 & 1 & 0.43 & 0.5228 \\
$X_{3}$ & 1.40 & 44.48 & 1 & 2.21 & 0.1582 \\
$X_{4}$ & -3.24 & 231.90 & 1 & 11.50 & 0.0040 \\
$X_{1} \times X_{2}$ & -0.21 & 0.65 & 1 & 0.032 & 0.8604 \\
$X_{1} \times X_{3}$ & -1.90 & 52.81 & 1 & 2.62 & 0.1265 \\
$X_{1} \times X_{4}$ & 1.54 & 33.68 & 1 & 1.67 & 0.2160 \\
$X_{2} \times X_{3}$ & -0.43 & 2.64 & 1 & 0.13 & 0.7227 \\
$X_{2} \times X_{4}$ & -1.33 & 25.97 & 1 & 1.29 & 0.2742 \\
$X_{3} \times X_{4}$ & 2.52 & 92.71 & 1 & 4.60 & 0.0483 \\
$X_{1} \times X_{1}$ & -6.55 & $1,169.38$ & 1 & 57.98 & $<0.0001$ \\
$X_{2} \times X_{2}$ & -10.27 & $2,874.51$ & 1 & 142.53 & $<0.0001$ \\
$X_{3} \times X_{3}$ & -10.41 & $2,952.02$ & 1 & 146.37 & $<0.0001$ \\
$X_{4} \times X_{4}$ & -10.65 & $3,091.94$ & 1 & 153.31 & $<0.0001$ \\
Residual & - & 302.52 & 15 & - & - \\
Lack of fit & - & 289.31 & 9 & 14.60 & 0.0020 \\
Pure error & - & 13.21 & 6 & - & - \\
Cor total & - & $8,348.00$ & 29 & - & - \\
\hline & & & & \\
\hline
\end{tabular}

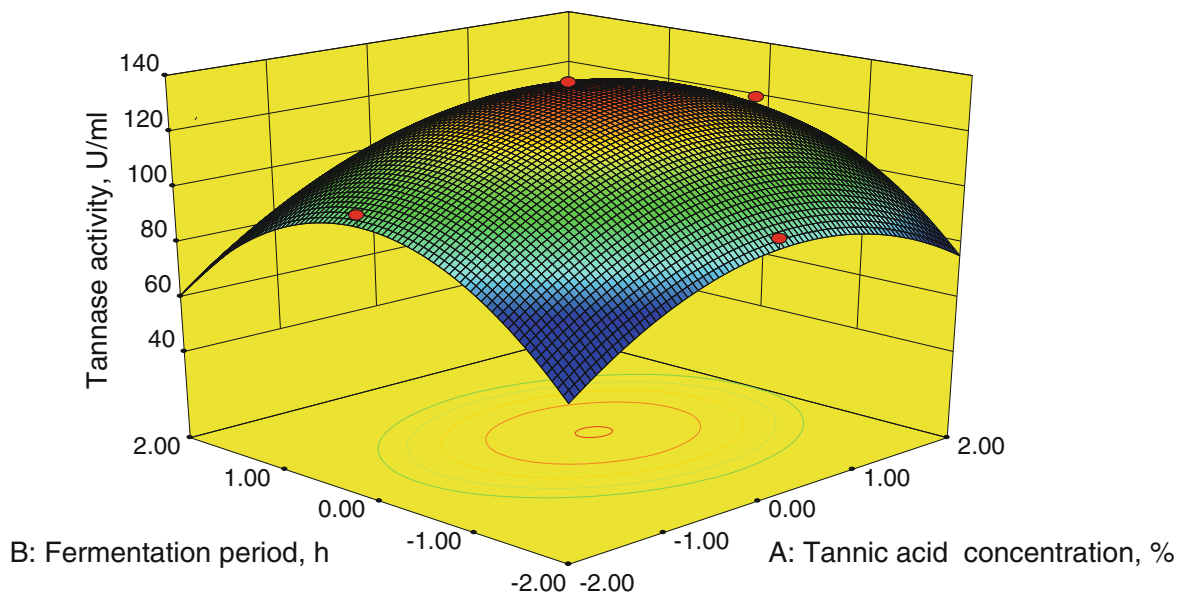

(Figs. 3, 5). Tannase activity was maximum in the acidic $\mathrm{pH}$ range, and its activity decreases in the alkaline range (Rodríguez et al. 2008; Raghuwanshi et al. 2011). The effect of $\mathrm{pH}$ on the activity of tannase may be attributed to its amino acids and active site which undergoes protonation or deprotonation; in addition, it may attributed to the conformational changes induced by amino acids ionization (Sabu et al. 2005).

The optimum conditions for the maximum production of tannase were determined by the response surface analyses and also estimated from the regression equation. The optimum conditions were tannic acid concentration, $3.22 \%$; fermentation period, $96 \mathrm{~h}$; temperature, $35.1{ }^{\circ} \mathrm{C}$; and $\mathrm{pH}$ 5.4. The predicted results were shown in Table 4. The predicted values from the regression equation closely agreed with the experimental values. Validation of the experimental model was tested by carrying out a batch experiment under optimal operating conditions. Three repeated experiments were performed and the results were compared. The tannase activity obtained from the experiments was very close to the response predicted by the regression model, which proves the validity of the model. At these optimized conditions the maximum tannase activity was found to be $139.3 \mathrm{U} / \mathrm{ml}$.

\section{Conclusions}

The response surface methodology was effectively applied for the production of tannase from A. flavus, MTCC 3783 
Fig. 3 3D plot showing the effect of tannic acid concentration and $\mathrm{pH}$ on tannase activity

Fig. 4 3D plot showing the effect of fermentation period and temperature on tannase activity

Fig. 5 3D plot showing the effect of temperature and $\mathrm{pH}$ on tannase activity
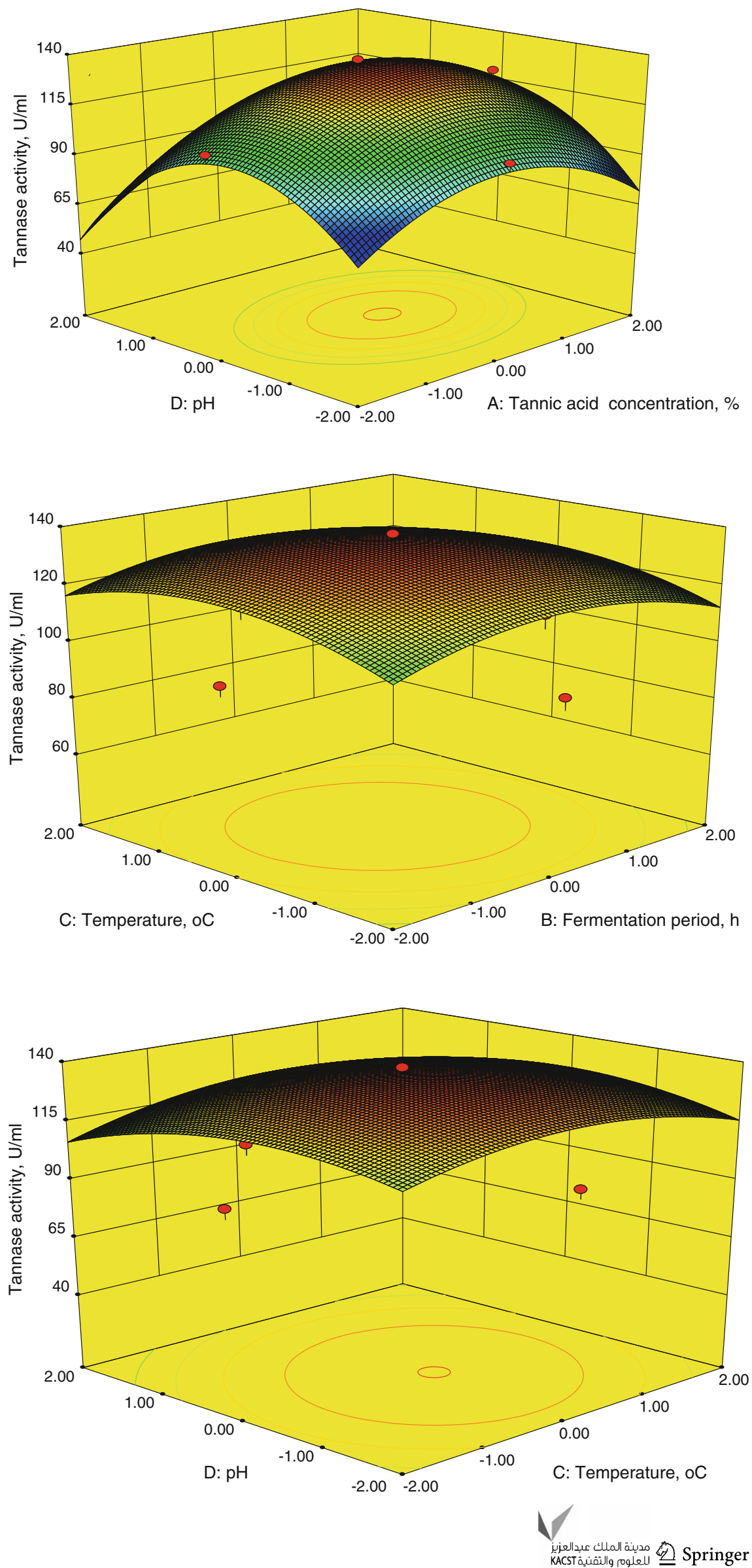
using tamarind seed powder as a substrate in submerged fermentation. Central composite design was employed to evaluate the effects of tannic acid concentration, fermentation period, temperature and $\mathrm{pH}$ on production of tannase by $A$. flavus. Using the above optimized nutrient solution, maximum tannase activity of $139.3 \mathrm{U} / \mathrm{ml}$ was obtained at the inducer tannic acid concentration of $3.22 \%$, temperature of $35.1{ }^{\circ} \mathrm{C}$, pH of 5.4, and fermentation period of $96 \mathrm{~h}$. The statistical design of experiment offers efficient methodology to identify the significant variables and to optimize the factors with minimum number of experiments for tannase production by $A$. flavus.

Acknowledgments The authors gratefully acknowledge the Bioprocess Research Laboratory, Department of Chemical Engineering, Annamalai University for providing the necessary facilities for the successful completion of this research work.

Conflict of interest The authors declare that they have no conflict of interest in the publication.

Open Access This article is distributed under the terms of the Creative Commons Attribution License which permits any use, distribution, and reproduction in any medium, provided the original author(s) and the source are credited.

\section{References}

Batra A, Saxena RK (2005) Potential tannase producers from the genera Aspergillus and Penicillium. Process Biochem 40:1553-1557

Beniwal V, Chhokar V (2010) Statistical optimization of culture conditions for tannase production by Aspergillus awamori MTCC 9299 under submerged fermentation. Asian J. Biotechnol 2(1):46-52

Couto SR, Sanroman MA (2006) Application of solid-state fermentation to food industry-a review. J Food Eng 76(3):291-302

Das Mohapatra PK, Mondal KC, Pati BR (2006) Production of tannase through submerged fermentation of tannin containing plant extracts by Bacillus licheniformis KBR6. Pol J Microbiol 55(4):297-401

Dilipkumar M, Rajasimman M, Rajamohan N (2011) Application of statistical design for the production of inulinase by Streptomyces sp. using pressmud. Front Chem Sci Eng 5(4):463-470
Lekha PK, Lonsane BK (1994) Comparative titres, location and properties of tannin acyl hydrolase produced by Aspergillus niger PKL104 in solid-state, liquid surface and submerged fermentations. Process Biochem 29:497-503

Lekha PK, Lonsane BK (1997) Production and application of tannin acyl hydrolase: state of the art. Adv Appl Microbiol 44:215-260

Mannan S, Fakhruĺ-Razi A, Alam MZ (2007) Optimization of process parameters for the bioconversion of activated sludge by Penicillium corylophilum using response surface methodology. J Environ Sci 19(1):23-28

Milva P, Lucia RL, Roberto A, Alessandro E, Guido P, Monia R, Arianna L, Antonio F, Simone G, Silvano EF (2010) Tannic acid degradation by bacterial strains Serratia sp. and Pantoea sp. isolated from olive mill waste mixtures. Int J Biodeter Biodegr 64:73-80

Mohan SK, Viruthagiri T, Arunkumar C (2012) Optimization and production of tannase by Aspergillus foetidus through submerged fermentation. Asian J Bio Pharma Res 4(2):22-29

Mondal KC, Banerjee D, Jana M, Pati BR (2001a) Colorimetric assay method for determination of tannin acyl hydrolase (EC.3.1.1.20) activity. Anal Biochem 295:168-171

Mondal KC, Banerjee D, Banerjee R, Pati B (2001b) Production and characterization of tannase from Bacillus cereus KBR9. J Gen Appl Microbiol 47:263-267

Murugan K, Saravanababu S, Arunachalam M (2007) Screening of tannin acyl hydrolase (E.C.3.1.1.20) producing tannery effluent fungal isolates using simple agar plate and SmF process. Bioresource Technol 98:946-949

Pan CM, Fan YT, Xing Y, Hou HW, Zhang ML (2008) Statistical optimization of process parameters on biohydrogen production from glucose by Clostridium sp. Fanp2. Bioresource Technol 99(8):3146-3154

Paranthaman R, Vidyalakshmi R, Murugesh S, Singaravadivel K (2009) Optimization of various culture media for tannase production in submerged fermentation by Aspergillus flavus. Adv Biol Res 3:34-39

Pinto GAS (2003) Production of tannase by Aspergillus niger. Ph.D. Thesis, Rio de Janeiro, p 213

Raghuwanshi S, Dutt K, Gupta P, Misra S, Saxena RK (2011) Bacillus sphaericus: the highest bacterial tannase producer with potential for gallic acid synthesis. J Biosci Bioeng 111:635-640

Rodríguez H, De las Rivas B, Gómez-Cordovés C, Munoz R (2008) Degradation of tannic acid by cell-free extracts of Lactobacillus plantarum. Food Chem 107:664-670

Sabu A, Kiran GS, Pandey A (2005) Purification and characterization of tannin acyl hydrolase from Aspergillus niger ATCC16620. Food Technol Biotechnol 43:133-138 